\title{
NOVAS DATAÇÕES PELO CARBONO 14 PARA AS OCUPAÇÕES HOLOCÉNICAS DO PRAZO (FREIXO DE NUMÃO, VILA NOVA DE FOZ CÔA, NORTE DE PORTUGAL)
}

\author{
SÉRGIO MONTEIRO-RODRIGUES(1)
}

Resumo

Summary

\begin{abstract}
Recentemente obtiveram-se cinco novas datações pelo radiocarbono para as ocupações holocénicas do sítio pré-histórico do Prazo. Quatro delas apresentam resultados compatíveis com os já divulgados em publicações anteriores. No conjunto, dispõe-se agora de uma série de vinte e seis datações ${ }^{14} \mathrm{C}$ que se consideram válidas. Estas datações permitem remeter a fase que se atribuiu ao Epipaleolítico para os finais do X/ meados do IX milénio cal BC; o Mesolítico mais antigo para o terceiro quartel do VIII milénio cal BC; o Mesolítico final para o período compreendido entre o segundo quartel do VII milénio cal BC e os meados do VI milénio cal BC; e o Neolítico Antigo para o intervalo balizado entre os finais do VI milénio cal BC e um momento indeterminado posterior ao terceiro quartel do $\mathrm{V}$ milénio cal $\mathrm{BC}$. Entre estes períodos com ocupações humanas observam-se intervalos temporais para os quais não existem datações absolutas. Sugere-se que este facto possa estar relacionado com as dinâmicas sedimentares do local no decurso do Holocénico e não necessariamente com um padrão de povoamento caracterizado pela descontinuidade.
\end{abstract}

Palavras-chave: Prazo; Holocénico; Cronologia ${ }^{14} \mathrm{C}$; Norte de Portugal.

\begin{abstract}
New radiocarbon dating for the Holocene occupations of the prehistoric site of Prazo (Freixo de Numão, Vila Nova de Foz Côa, Northern Portugal)

Recently, five new radiocarbon dates for the Holocene occupations of the prehistoric site of Prazo were obtained. Four of them show results that are consistent with those previously published. At the moment, there are twenty-six ${ }^{14} \mathrm{C}$ dates that are considered to be valid. These dates assign the supposed Epipalaeolithic to the end of the $10^{\text {th }} /$ middle of the $9^{\text {th }}$ millennium cal BC; the earliest Mesolithic to the third quarter of the $8^{\text {th }}$ millennium cal $\mathrm{BC}$; the late Mesolithic to the interval between the second quarter of the $7^{\text {th }}$ millennium cal $\mathrm{BC}$ and the middle of the $6^{\text {th }}$ millennium cal $\mathrm{BC}$; and the early Neolithic to the interval between the end of the $6^{\text {th }}$ millennium cal $\mathrm{BC}$ and an undetermined moment after the third quarter of the $5^{\text {th }}$ millennium cal BC. Among these periods with human occupation there are intervals for which there is no absolute dating. It is suggested that this may be related to the sedimentary dynamics of the site during the Holocene and not necessarily to a settlement pattern characterized by discontinuity.
\end{abstract}

Keywords: Prazo; Holocene; ${ }^{14} \mathrm{C}$ Chronology; Northern Portugal.

O tempo em si não é nada; o tempo é apenas o que fazemos dele. Ana Sã, 2010

\section{INTRODUÇÃo}

A investigação desenvolvida no sítio pré-histórico do Prazo (Fig. 1), iniciada em 1997, permitiu identificar uma série de ocupações balizadas entre o Paleolítico Superior e o Neolítico Antigo. Aliás, um dos principais contributos desta estação arqueológica foi, precisamente, ter fornecido vestígios de ocupações mesolíticas, até então desconhecidas no interior do território nacional, o que possibilitou que se avançassem novos modelos explicativos sobre o processo de neolitização no Nordeste de Portugal. Neste sentido, as diversas publicações divulgadas até ao momento centraram-se sobretudo nos "níveis" do Neolítico Antigo e nos do Mesolítico Final (MONTEIRO-RODRIGUES 2000, 2002, 2008, 2010, 2011; Monteiro-Rodrigues E ANGELUCCI 2004; MonTEIRO-Rodrigues et al. 2008; LÓPEZ SÁEZ et al. 2006-2007). As restantes ocupações, nomeadamente as do Paleolítico Superior e as da fase mais antiga do Mesolítico (MONTEIRO-RodRIGUES 2008), serão em breve alvo de estudo detalhado.

(1) Faculdade de Letras da Universidade do Porto. Via Panorâmica, s/n, 4150-564 Porto, Portugal. Investigador integrado do Centro de Estudos Arqueológicos das Universidades de Coimbra e Porto (CEAUCP). sergiomonteirorodrigues@gmail.com 


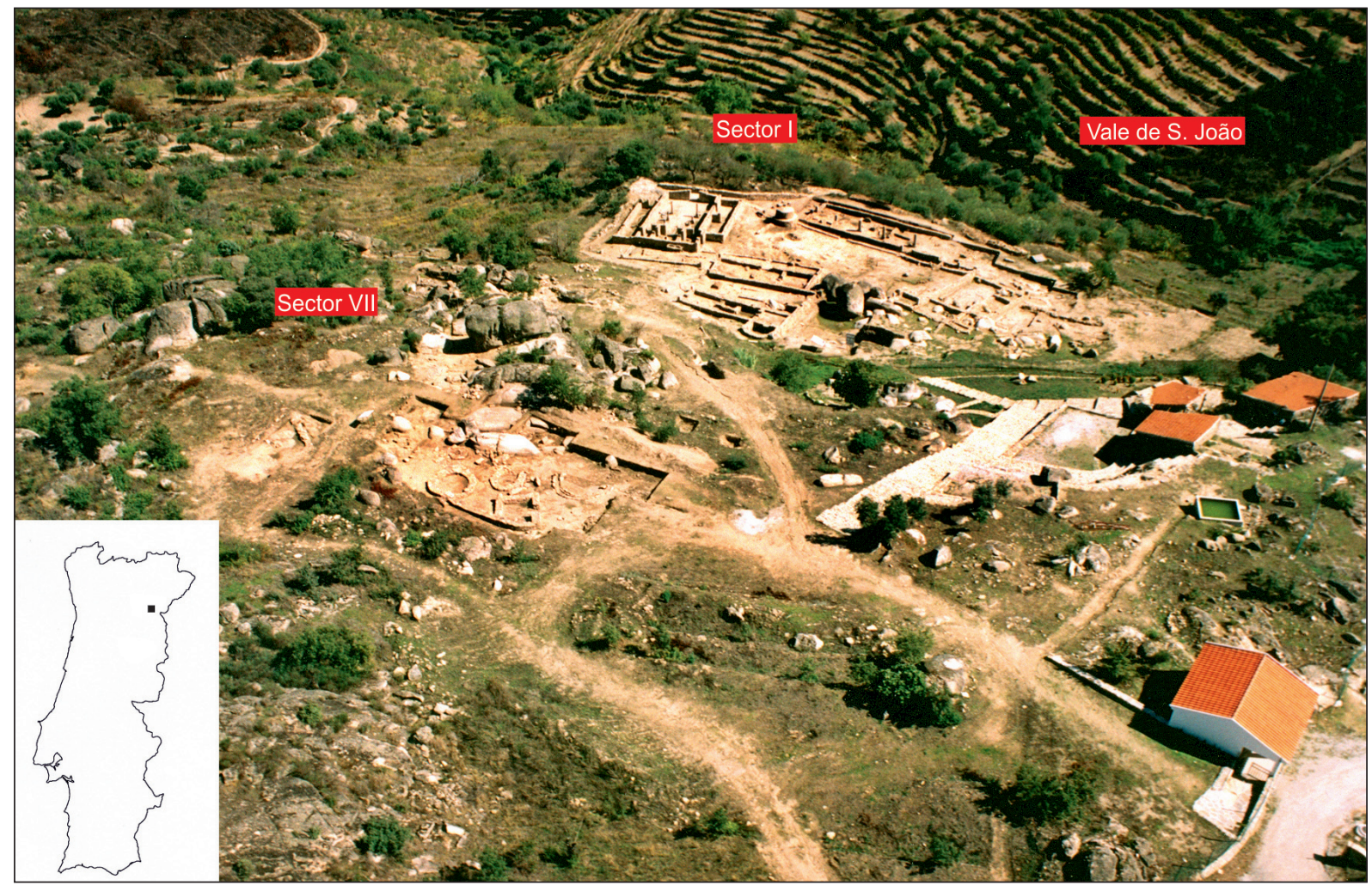

Fig. 1. Localização do sítio pré-histórico do Prazo (freguesia de Freixo de Numão, concelho de Vila Nova de Foz Côa, distrito da Guarda). Vista aérea oblíqua da estação (vista de SW). Sectores escavados (sector I e sector VII) e vale da ribeira de S. João (subafluente do rio Douro).

Fig. 1. Location of the prehistoric site of Prazo (Freixo de Numão, Vila Nova de Foz Côa, Guarda). Oblique aerial view of the site (view from SW). Excavated sectors (sector I and sector VII) and the S. João valley (tributary of Rio Douro).

Uma primeira análise das datações absolutas relativas às várias ocupações do Prazo foi feita no contexto de um estudo geoarqueológico levado a cabo em 2002. Nas publicações que dele resultaram (ANGELUCCI E MONTEIRO-RODRIGUES 2003; MONTEIRO-RODRIGUES E ANGELUCCI 2004) divulgaram-se vinte e oito datações ${ }^{14} \mathrm{C}$, obtidas nos laboratórios do ITN (Portugal), do CSIC (Espanha), de Gröningen (Holanda) e de Uppsala (Suécia). Excluídas as datações que então se consideraram anómalas - isto é, as que remetiam para períodos pós pré-históricos (3 casos), as que remetiam para períodos pré-históricos não testemunhados arqueologicamente (1 caso), as obtidas a partir de osso queimado (não calcinado) pela técnica denominada Dating of Cremated Bones (LANTING et al. 2001) (3 casos) e as resultantes de amostras constituídas por carvões que se encontraram dispersos na quadrícula de $1 \mathrm{~m}^{2}$ (1 caso) - avançou-se, preliminarmente, uma sequência cronológica que colocava o Neolítico Antigo nos meados do V milénio cal BC, o Mesolítico Final na primeira metade do VI milénio cal BC, o Mesolítico nos meados do VIII milénio cal $\mathrm{BC}$ e o Epipaleolítico (?) nos inícios do IX milénio cal BC (ANGELUCCI E Monteiro-Rodrigues 2003; MonteIRO-Rodrigues E ANGELUCCI 2004).

Mais tarde, em 2006, no âmbito de um trabalho académico (MONTEIRO-RODRIGUES 2008), obtiveram-se mais três datações pelo radiocarbono (uma das quais anómala), desta vez processadas no laboratório da Universidade de Waikato (Nova Zelândia). Paralelamente repescaram-se algumas datações pouco valorizadas nas publicações de 2003 e 2004, uma vez que a reapreciação detalhada do registo arqueológico de campo possibilitou a clarificação dos contextos das respectivas amostras.

Apesar de uma boa parte das datações do Prazo ter sido obtida a partir de amostras de carvão constituídas por diversas espécies vegetais, nomeadamente de "vida longa" (note-se que muitas das datações foram produzidas numa altura em que os problemas inerentes ao "efeito de madeira antiga" não tinham sido ainda amplamente divulgados - veja-se,

As datações divulgadas foram efectivamente 30. Contudo, duas delas dizem respeito ao sector XXIII e ao Abrigo 1 do sector Prazo II, os quais são irrelevantes para as questões abordadas neste texto (ver MONTEIRO-RODRIGUES, 2008). 
por exemplo, BERNABEU et al. 1999, 2001; ZILHÃO 2001; CARVAlHo 2003), e também a partir de amostras cujas espécies não foram determinadas, optou-se pela sua validação essencialmente por quatro razões principais (MONTEIRO-RODRIGUES 2008, 2011):

(1) Os respectivos valores radiométricos revelaram-se próximos ou mesmo semelhantes a outros da mesma unidade estratigráfica, obtidos a partir de amostras de "vida curta" e de amostras de "longevidade reduzida" - isto é, amostras de espécies que não sendo de "vida curta" (animais, plantas anuais, sementes, frutos, etc.) possuem uma longevidade bastante mais reduzida comparativamente à de outros taxa identificados na estação (p.e. $P i$ nus ou Quercus). Esta longevidade não tem, em princípio, grande expressão nos resultados de radiocarbono, desde logo devido à imprecisão inerente a este método de datação (inf. pess. de Mónica Ruiz, Setembro de 2012).

(2) De acordo com informações decorrentes do estudo antracológico levado a cabo no Prazo, há a probabilidade do material lenhoso das espécies arbóreas utilizado nas pequenas lareiras exumadas corresponder essencialmente aos ramos mais jovens e não aos troncos principais, pelo que, neste caso, as datações não seriam afectadas pelo "efeito de madeira antiga” (MonTEIRO-Rodrigues 2008, 2011).

(3) As datações obtidas são compatíveis com a realidade arqueológica observada.

(4) Futuramente, estas datações poderão ser comparadas com resultados radiométricos que venham a ser produzidos para a região duriense, sendo então possível proceder a eventuais "afinações" da cronologia agora estabelecida.

Em 2011-2012, no quadro dos projectos de investigação DOMATLANTICA - "La implantación de las especies domésticas en la Europa atlántica: cronología e impacto en la dieta humana"2 e COASTTRAN - "Coastal transitions: A comparative approach to the processes of neolithization in Atlantic Europe"3, realizaram-se mais cinco datações por AMS no laboratório da Universidade de Oxford, que agora se publicam. Diversas amostras de carvão foram previamente estudadas do ponto de vista antracológico (estudo realizado por Mónica Ruiz, CSIC, Espanha) com o objectivo de garantir que apenas seriam datadas espécies vegetais de "vida curta"/“"longevidade reduzida". Com a excepção de uma datação, que forneceu um valor que remete para um período posterior a 1950 $\mathrm{AD}$ (OxA-24781), as restantes quatro apresentaram resultados perfeitamente concordantes com outros obtidos anteriormente, pelo que contribuem para a confirmação do modelo cronológico que tem vindo a ser avançado para o Prazo (MONTEIRO-RODRIGUES 2008, 2011; MONTEIRO-RodRIGUES E ANGELUCCI 2004; MONTEIRO-RODRIGUES et al. 2008).

\section{O Contexto das Amostras datadas}

A maior parte das amostras datadas articula-se com áreas de combustão (para mais detalhes sobre os contextos das amostras ver MONTEIRO-RODRIGUES 2008 e 2011), nuns casos delimitadas por estrutura pétrea, noutros casos sem qualquer delimitação ou apenas parcialmente delimitadas (Fig. 2 - Neolítico Antigo: amostras S71, S91, S50, S61, S3, S4; Fig. 3 - Mesolítico Final: amostras S22, S15, S21, 97-2; Fig. 4 - Mesolítico "antigo": amostras S87, A2, S5, S30; Fig. 5 - Epipaleolítico (?): amostra S2). De um modo geral, estas estruturas denotam, como foi anteriormente sublinhado (idem), um baixo investimento em termos construtivos, pelo que poderão documentar comunidades com elevada mobilidade.

As amostras S7A-VII e S7-VII não se associavam a qualquer estrutura pétrea uma vez que no sector de onde provêm (sector VII) tais estruturas são praticamente inexistentes. A amostra S7A-VII surgiu junto de um bloco de granito isolado, que encostava lateralmente ao bed-rock (Fig. 6); a amostra S7-VII foi retirada de uma camada areno-argilosa que poderá ser um resquício de um "piso" de terra batida (?), posicionado na base do depósito arqueológico (Fig. 6) (Monteiro-Rodrigues 2008 e 2011). Todavia, ambas as amostras conectam-se claramente com a única unidade estratigráfica neolítica existente no sector VII. Relativamente à raridade das estruturas, esta poderá ser consequência de processos de coluvionamento dos depósitos arqueológicos ou então traduzir, como se disse, o carácter efémero das "construções" do Prazo (idem).

A amostra A4 - relacionada com a unidade geoarqueológica U4a (Mesolítico Final) - provém de um

Referência: HAR2008-06477-C03-01; 2008-2011; Coord: Pablo Arias, Universidade da Cantábria, Espanha. Projecto no âmbito do VI Plan Nacional de Investigación Científica, Desarrollo e Innovación Tecnológica 2008-2011 (Subprograma de Proyectos de Investigación Fundamental no Orientada) do Ministerio de Ciencia e Innovación.

3 Referência: HAR2011-29907-C03-00; 2012-2014; Coord: Pablo Arias, Universidade da Cantábria, Espanha. Projecto no âmbito do VI Plan Nacional de Investigación Cientifica, Desarrollo e Innovación Tecnológica 2008-2011 (Subprograma de Proyectos de Investigación Fundamental no Orientada) do Ministerio de Ciencia e Innovación. 


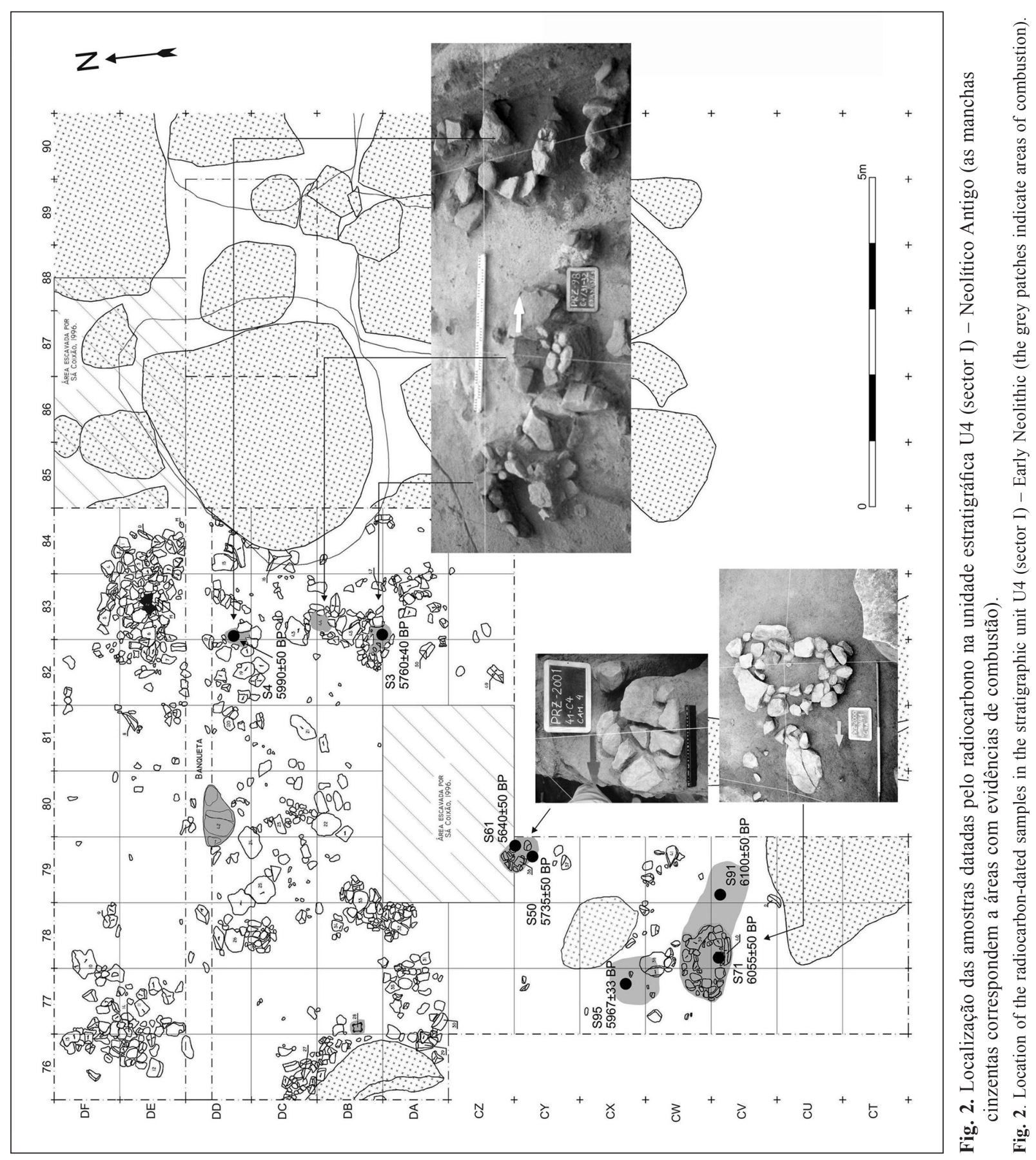




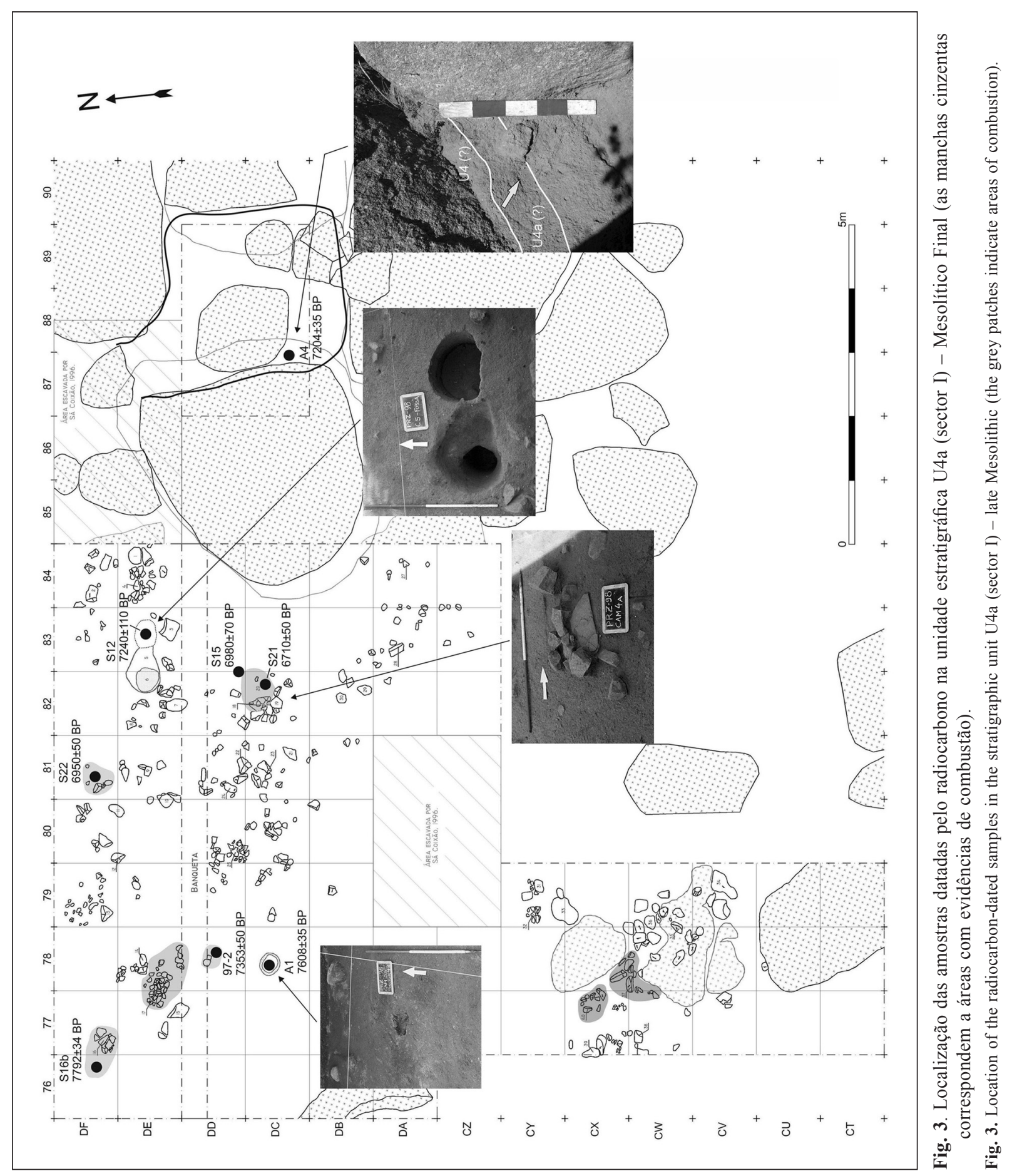




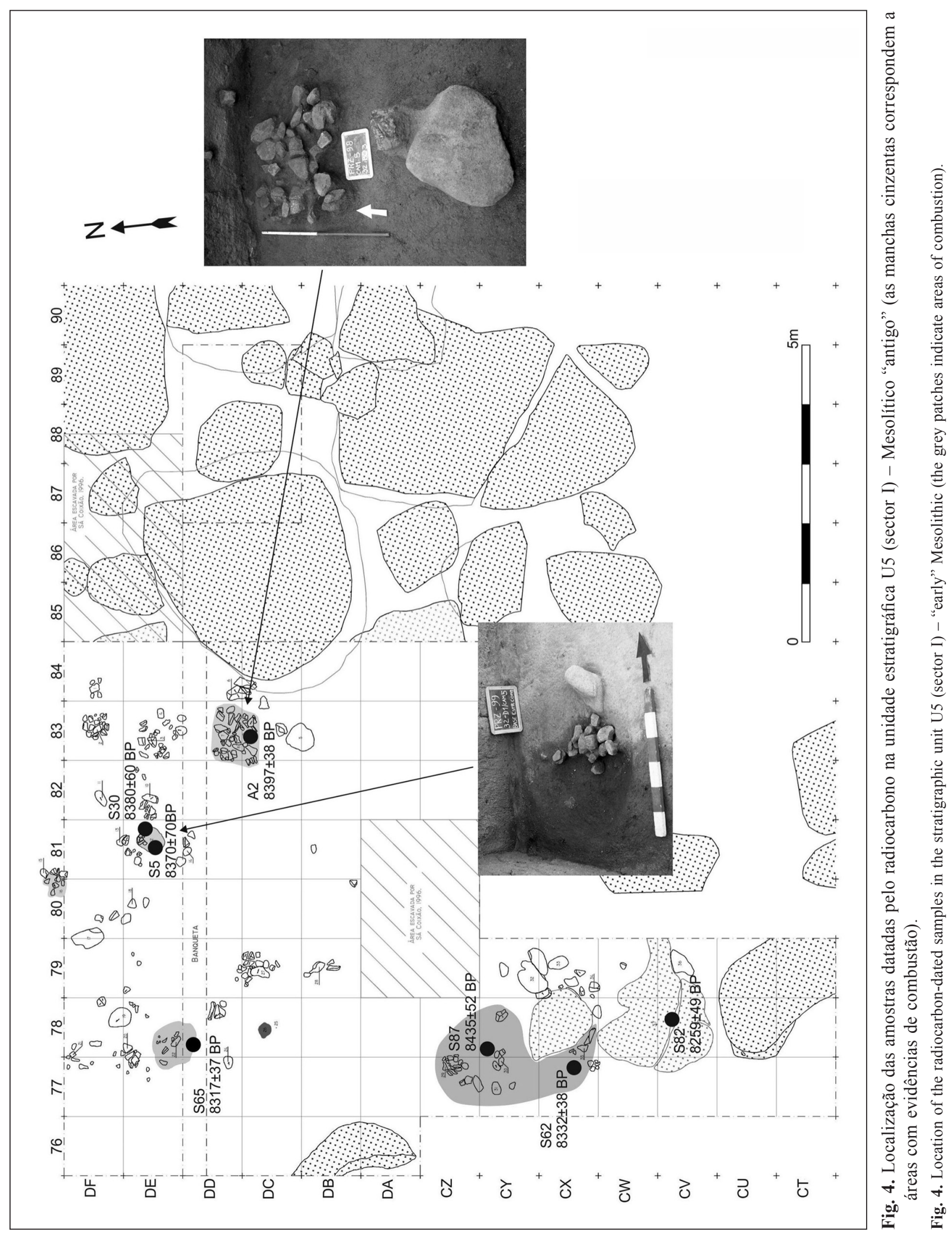




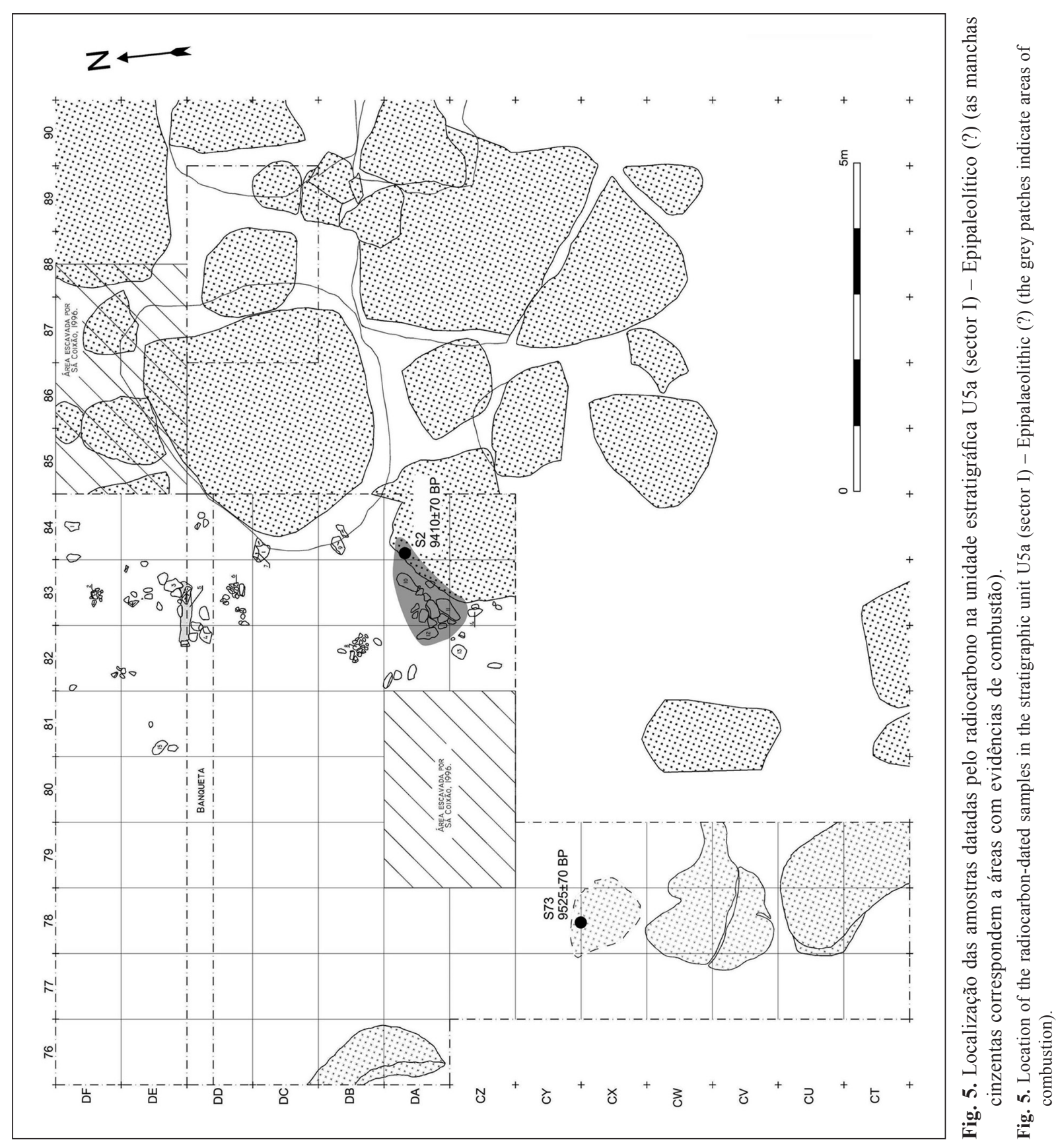




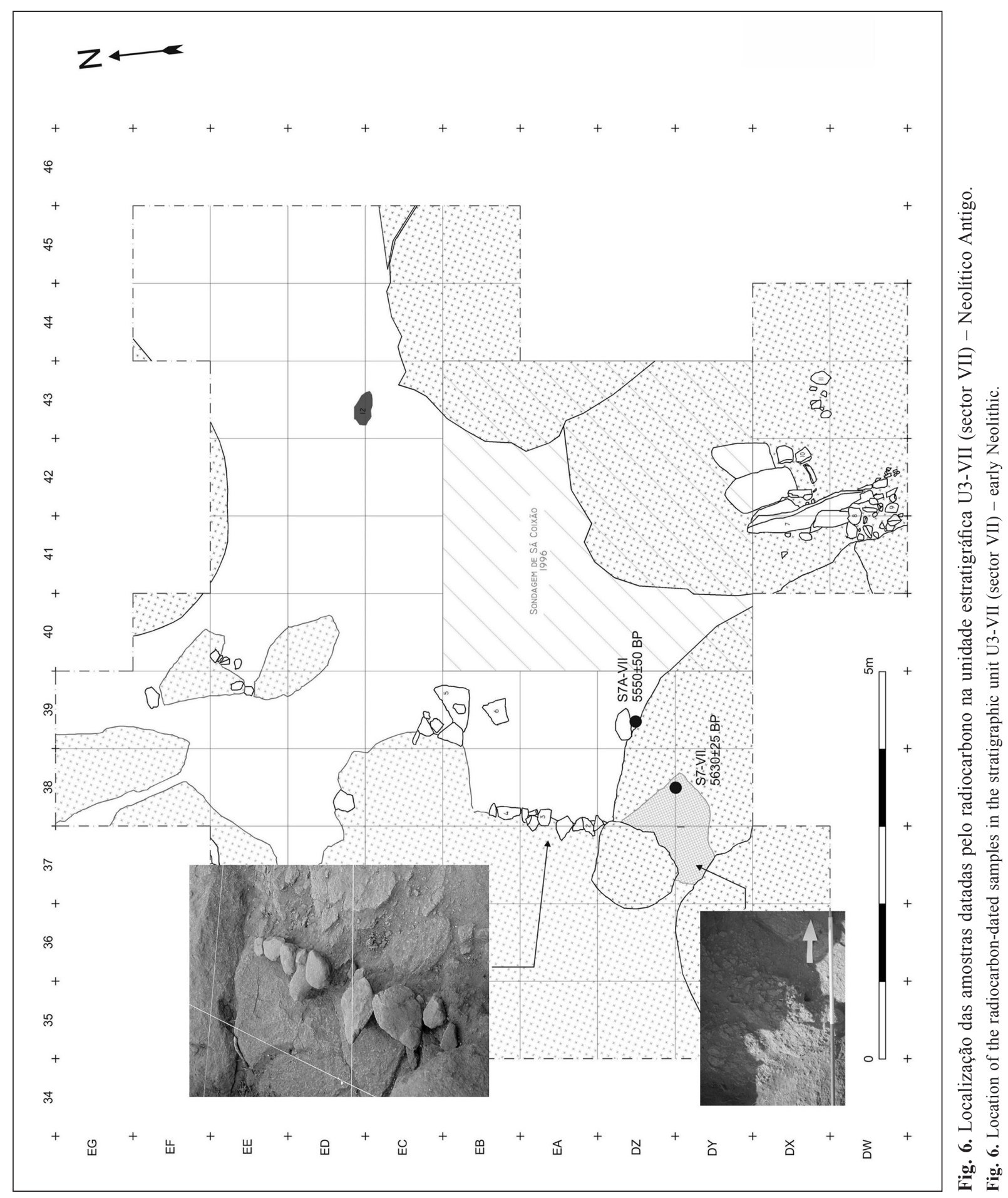


pequeno perfil estratigráfico localizado no interior do espaço delimitado pelos enormes blocos de granito do sector I (Fig. 3). Apesar de este espaço revelar claras perturbações estratigráficas decorrentes das sucessivas ocupações que ali tiveram lugar, o perfil, devido à sua posição resguardada, conservou a sequência sedimentar original. A presença de indicadores de fogo nesta área, tais como carvões, ossos queimados e termoclastos (fragmentos de granito termoalterado, com coloração avermelhada, nalguns casos fuliginosos e seixos de quartzito com fracturas de origem térmica) permitiu associar a amostra A4 a uma das inúmeras combustões que aqui terão sido realizadas.

A amostra S12 foi recolhida no interior da fossa do Neolítico Antigo (Fig. 3), relacionando-se, todavia, com a unidade U4a (Mesolítico Final), a qual é atravessada por aquela estrutura. A natureza arenosa dos sedimentos do Prazo terá favorecido a desagregação da parede da fossa, levando ao surgimento de carvões mais antigos no interior de uma estrutura mais recente (MONTEIRO-RODRIGUES 2008 e 2011). A amostra A1 provém também de uma estrutura negativa, neste caso da base de um buraco de poste aberto na unidade U4a (Fig. 3).

A amostra S82 foi detectada sobre alterite granítica, não tendo sido possível associá-la a qualquer estrutura. No entanto, a presença de um bloco de granito na sua proximidade sugere que sobre a referida alterite tenha existido uma pequena lareira parcialmente delimitada por pedras (Fig. 4).

A amostra S73 surgiu sob um grande bloco de granito que assenta praticamente sobre a superfície de erosão que, no Prazo, separa a sequência sedimentar plistocénica (com os vestígios arqueológicos atribuídos ao Paleolítico Superior) da sequência holocénica, pelo que foi relacionada com processos deposicionais dos inícios deste último período (Fig. 5) (Monteiro-Rodrigues E ANGELUCCI 2004; MONTEIRO-RODRIGUES 2008, 2011).

No que diz respeito às amostras S95, S16b, S65 e S62, obtidas no âmbito dos referidos projectos DOMATLANTICA e COASTTRAN, importa tecer algumas considerações mais pormenorizadas relativamente ao seu contexto uma vez que, como se disse, constituem um conjunto inédito.

As amostras S62 e S95 foram recolhidas numa zona onde existiam pelo menos três áreas de combustão sobrepostas: uma superior, com estrutura pétrea de contorno ovalar, rodeada por diversas concentrações de carvões, associada à unidade U4 (Neolítico Antigo) (Fig. 2, quadrículas CW77/78 e CX77/78); uma intermédia, definida por pequenos aglomerados de pedras, associada à unidade U4a (Mesolítico Final) (Fig. 3, quadrículas CW77/78 e CX77); e uma inferior, com alguns fragmentos de granito avulsos, associada à unidade U5 (Mesolítico) (Fig. 4, quadrículas CX77/78, CY77/78 e CZ77/78). Uma vez que as manchas carbonosas das áreas de combustão eram verticalmente contínuas tornou-se difícil precisar o contexto estratigráfico de cada uma das amostras. Em todo o caso, a amostra S62 foi relacionada com a unidade U4 (Neolítico Antigo), mais precisamente com a concentração de carvões da quadrícula CX77 (Fig. 2); a amostra S95 associou-se à unidade U4a (Mesolítico Final), a um pequeno conjunto de pedras localizado naquela mesma quadrícula (Fig. 3). No entanto, não se excluiu a possibilidade da amostra S95 poder articular-se, alternativamente, com a unidade U4 (Neolítico Antigo), uma vez que se considerou que a sua posição estratigráfica poderia decorrer do movimento vertical descendente do material antracológico. Efectivamente, o respectivo valor radiométrico veio confirmar esta última hipótese (Fig. 2). A amostra S62, por seu turno, forneceu uma datação que a conecta com a área de combustão do nível U5 (Mesolítico) (Fig. 4).

Com a amostra S16b passou-se uma situação semelhante à ocorrida com a amostra S62: apesar de recolhida durante a escavação de um empedrado da unidade estratigráfica U4 (Neolítico Antigo) (Fig. 2, quadrículas DE76/77 e DF76/77), os valores de ${ }^{14} \mathrm{C}$ remetem-na para o Mesolítico Final. Ao que tudo indica, o material datado relaciona-se com uma mancha carbonosa que circunda um pequeno aglomerado pétreo imediatamente subjacente ao referido empedrado neolítico (Fig. 3, quadricula DF77).

A amostra S65 provém também de uma zona com duas lareiras sobrepostas, uma pertencente à unidade U4a (Mesolítico Final) (Fig. 3, quadrícula DE77/78) e outra à unidade U5 (Mesolítico) (Fig. 4, quadrícula DE77/78). Apesar de se ter conseguido estabelecer o limite estratigráfico entre as componentes pétreas das lareiras, o mesmo não foi possível relativamente ao depósito orgânico que as envolvia, uma vez que este revelou continuidade ao longo das duas camadas. Tendo como referência genérica a cota do carvão recolhido, atribuiu-se a amostra S65 à unidade U4a (Mesolítico Final), não se descartando, todavia, a possibilidade de ela datar a unidade U5 (Mesolítico), o que de facto se veio a verificar.

Como foi salientado no trabalho de 2008 (MoNTEIRO-RODRIGUES 2008, 2011), a descontextualização dos carvões (e, seguramente, de outros materiais) nas áreas onde existe sobreposição estratigráfica de estruturas de combustão parece ser um fenómeno bastante frequente. Em princípio, esta descontextualização decorre da intensa antropização a que estas áreas terão estado sujeitas. De acordo com Jean-Pierre Texier (2000), a construção, reconstrução e 
utilização de estruturas de combustão implica toda uma série de acções mecânicas que podem afectar depósitos preexistentes, ocorrendo, consequentemente, transferência de material entre diferentes estratos. Esta situação torna-se ainda mais frequente nos casos em que as unidades arqueoestratigráficas têm pouca espessura, tal como sucede no Prazo (MONTEIRO-RoDRIGUES E ANGELUCCI 2004; MONTEIRO-RODRIGUES 2008). Para além da actividade antrópica, ocorrem igualmente processos pós-deposicionais naturais, normalmente ligados à bioturbação, à percolação e a movimentos de origem gravítica. Deste modo, a validade dos dados radiométricos resultantes das áreas de combustão depende em grande medida da existência de uma série significativa de datações de referência com as quais eles se possam articular. No caso específico das amostras S95, S16b, S65 e S62, os respectivos valores de ${ }^{14} \mathrm{C}$ revelaram-se claramente compatíveis com os anteriormente obtidos, indo, aliás, ao encontro da cronologia já avançada noutras publicações relativas a esta estação. Seja como for, não se pode descorar que a circulação de material carbonoso entre camadas pode diminuir a fiabilidade das datações, sobretudo das obtidas a partir de amostras compostas por diversos carvões. Efectivamente, os respectivos resultados de ${ }^{14} \mathrm{C}$ poderão sofrer "desvios" devido à presença eventual de elementos carbonosos com idades distintas.

\section{CRONOlOgia das OCUPAÇões PRÉ- -Históricas do Prazo}

Actualmente, o sítio pré-histórico do Prazo dispõe de 26 datações pelo radiocarbono consideradas válidas (Tabela 1). Para a sua calibração utilizou-se o programa informático CALIB rev. 6.0.1 (STUIVER E REIMER 1993, 2011) e a curva de calibração IntCal09 (REIMER et al. 2009). Os intervalos de confiança valorizados foram os de $2 \sigma$, o que significa que o que se pretendeu datar tem $95,4 \%$ de probabilidade de se encontrar dentro do intervalo temporal aferido pela calibração das datações ${ }^{14} \mathrm{C}$ convencionais. As operações estatísticas a que se recorreu foram a soma das distribuições de probabilidade e o cálculo de médias ponderadas. A primeira teve como objectivo determinar o intervalo temporal máximo definido por um dado conjunto de resultados de radiocarbono. A segunda foi usada num único caso em que a totalidade das datações eram estatisticamente semelhantes (pelo que também se apresentam os resultados dos testes $\mathrm{T}$ e $\mathrm{Xi}^{2}$ e os graus de liberdade - Gl), reportando-se, em princípio, a um mesmo episódio de ocupação (WARD E WILSON 1978; WILSON E WARD 1981).

\section{Epipaleolítico (?)}

Como foi referido, a unidade U5a inicia a sequência sedimentar holocénica do Prazo (MONTEIRO-RODRIGUES 2008, 2011; MONTEIRO-RODRIGUES E ANGELUCCI 2004). De acordo com as duas datações obtidas, os processos de sedimentação de vertente que estiveram na génese deste depósito, e que conservaram os respectivos vestígios arqueológicos, terão ocorrido no período definido pelo intervalo 9150-8550 cal BC (Fig. 7). Apesar das datações serem estatisticamente semelhantes, não há dados que permitam afirmar que se relacionam com o mesmo "momento" de ocupação.

\section{Mesolítico (fase "antiga")}

$\mathrm{O}$ período que se convencionou denominar $\mathrm{Me}$ solítico "antigo" - representado pelos vestígios da unidade geoarqueológica U5 - foi balizado cronologicamente a partir de sete datações estatisticamente semelhantes para o grau de confiança de $2 \sigma(\mathrm{T}=9,00$; $\mathrm{Xi}^{2}(.05)=12,6 ; \mathrm{Gl}=6$ ) (Fig. 7). Estas datações parecem documentar uma "única" ocupação ocorrida algures entre 7497 e 7353 cal BC 2o, intervalo que resulta da calibração da média ponderada dos vários resultados radiométricos disponíveis $(8351 \pm 17 \mathrm{BP})$. Em alternativa, as datações poderiam testemunhar diferentes ocupações temporalmente muito próximas entre si. No entanto, as limitações subjacentes ao grau de resolução do método do ${ }^{14} \mathrm{C}$, traduzidas na grande amplitude dos intervalos de probabilidades, inviabilizam a confirmação desta hipótese. Pelo facto das datações serem na sua totalidade estatisticamente semelhantes e estarem associadas a estruturas espacialmente próximas, optou-se pela primeira possibilidade.

\section{Mesolítico Final}

Para o Mesolítico Final (unidade U4a) há oito datações que documentam, provavelmente, distintos episódios de ocupação do Prazo (Fig. 7). Considerando a soma das distribuições de probabilidade das datas obtidas, tais ocupações terão ocorrido dentro de um intervalo temporal compreendido entre $6681 \mathrm{e}$ 5557 cal BC (2o). Dentro deste período, e igualmente para o grau de confiança de $2 \sigma$, estabelecem-se os intervalos de 6681-6587 cal BC (10\%), 6583-6568 cal BC $(0,6 \%), 6543-6533$ cal BC $(0,4 \%), 6501-6420$ cal BC (12\%), 6357-6292 cal BC (3\%), 6269-5728 cal BC $(61 \%)$ e $5714-5557$ cal BC $(12 \%)$.

A existência de dois conjuntos de datações estatisticamente semelhantes, constituídos, respectivamente, pelos resultados radiométricos das amostras A4, S12 
Tabela 1. Datações ${ }^{14} \mathrm{C}$ para o sítio pré-histórico do Prazo.

Table 1. ${ }^{14} \mathrm{C}$ dating for the prehistoric site of Prazo.

\begin{tabular}{|c|c|c|c|c|c|c|c|}
\hline Ref. Am. & UE & Ref. Lab. & Mét. & Rconv. BP & $\begin{array}{c}\text { Cal BP 2 } \sigma \\
\text { (Distrib. probab.) }\end{array}$ & $\begin{array}{c}\text { Cal BC } 2 \sigma \\
\text { (Distrib. probab.) }\end{array}$ & Mat. Datado \\
\hline \multicolumn{8}{|l|}{ Sector VII } \\
\hline S7A-VII & U3-VII/ NA & Ua-20491 & AMS & $5550 \pm 50$ & $6279-6439(1,000)$ & $4490-4330(1,000)$ & $\begin{array}{l}\text { Bolbo indeterminado, Cistaceae, } \\
\text { Cortiça, Erica arborea, Fabaceae, } \\
\text { Quercus sp. }\end{array}$ \\
\hline S7-VII & U3-VII/ NA & GrN-26404 & c & $5630 \pm 25$ & $\begin{array}{l}6318-6375(0,260) \\
6388-6477(0,740)\end{array}$ & $\begin{array}{l}4528-4439(0,740) \\
4426-4369(0,259)\end{array}$ & Arbutus unedo (Medronhos) ${ }^{\star}$ \\
\hline \multicolumn{8}{|l|}{ Sector I } \\
\hline S61 & $\mathrm{U} 4 / \mathrm{NA}$ & Ua-20493 & AMS & $5640 \pm 50$ & $\begin{array}{l}6305-6511(0,981) \\
6516-6532(0,018)\end{array}$ & $\begin{array}{l}4583-4567(0,018) \\
4562-4356(0,981)\end{array}$ & Quercus suber \\
\hline S50 & U4/ NA & Ua-20492 & AMS & $5735 \pm 50$ & $\begin{array}{l}6412-6429(0,032) \\
6431-6644(0,963) \\
6647-6651(0,005)\end{array}$ & $\begin{array}{l}4702-4698(0,004) \\
4695-4482(0,963) \\
4480-4463(0,031)\end{array}$ & $\begin{array}{l}\text { Pinus pinaster/ pinea, Quercus } \\
\text { suber, casca de árvore indet. }\end{array}$ \\
\hline S3 & U4/ NA & GrA-16131 & AMS & $5760 \pm 40$ & $\begin{array}{l}6454-6458(0,007) \\
6465-6659(0,993)\end{array}$ & $\begin{array}{l}4710-4516(0,992) \\
4509-4505(0,007)\end{array}$ & Osso carbonizado* \\
\hline S95 & U4/ NA & OXA-24783 & AMS & $5967 \pm 33$ & $\begin{array}{l}6680-6681(0,001) \\
6693-6702(0,009) \\
6718-6893(0,990) \\
\end{array}$ & $\begin{array}{l}4944-4769(0,989) \\
4753-4744(0,009) \\
4732-4731(0,000)\end{array}$ & Prunus sp.* \\
\hline S4 & U4/ NA & GrA-15984 & AMS & $5990 \pm 50$ & $\begin{array}{l}6678-6684(0,006) \\
6690-6704(0,014) \\
6716-6950(0,980)\end{array}$ & $\begin{array}{l}5001-4767(0,980) \\
4755-4741(0,014) \\
4735-4729(0,005)\end{array}$ & Osso carbonizado* \\
\hline S71 & $\mathrm{U} 4 / \mathrm{NA}$ & Ua-20494 & AMS & $6055 \pm 50$ & $\begin{array}{l}6748-6767(0,014) \\
6773-7024(0,949) \\
7118-7153(0,037)\end{array}$ & $\begin{array}{l}5204-5169(0,036) \\
5075-4824(0,949) \\
4818-4799(0,013)\end{array}$ & $\begin{array}{l}\text { Arbutus unedo, Cistaceae, } \\
\text { Gimnospérmica, Pinus pinaster/ } \\
\text { pinea, indet. }\end{array}$ \\
\hline s91 & U4/ NA & Ua-20496 & AMS & $6100 \pm 50$ & $\begin{array}{l}6805-6813(0,011) \\
6852-7159(0,989)\end{array}$ & $\begin{array}{l}5210-4903(0,989) \\
4864-4856(0,010)\end{array}$ & $\begin{array}{l}\text { Pinus sp. (fragmento de pinha), } \\
\text { Pinus pinasterl pinea, Quercus } \\
\text { suber }\end{array}$ \\
\hline S21 & U4a/ MF & GrN-26400 & C & $6710 \pm 50$ & $7492-7664(1,000)$ & $5715-5543(1,000)$ & Carvão vegetal \\
\hline s22 & U4a/ MF & GrA-18787 & AMS & $6950 \pm 50$ & $\begin{array}{l}7679-7868(0,935) \\
7898-7925(0,065)\end{array}$ & $\begin{array}{l}5976-5949(0,064) \\
5919-5730(0,935)\end{array}$ & Fragmento de semente indet. ${ }^{*}$ \\
\hline S15 & U4a/ MF & GrA-18866 & AMS & $6980 \pm 70$ & $7680-7940(1,000)$ & $5991-5731(1,000)$ & Pinus pinaster/ pinea \\
\hline A4 & $\mathrm{U} 4 \mathrm{a} / \mathrm{MF}$ & CSIC-1622 & c & $7204 \pm 35$ & $\begin{array}{l}7952-8062(0,881) \\
8088-8113(0,051) \\
8117-8134(0,032) \\
8137-8155(0,036)\end{array}$ & $\begin{array}{l}6206-6188(0,036) \\
6185-6168(0,031) \\
6164-6139(0,050) \\
6113-6003(0,881)\end{array}$ & Quercus sp. \\
\hline S12 & $\mathrm{U} 4 \mathrm{a} / \mathrm{MF}$ & GrN-26398 & C & $7240 \pm 110$ & $\begin{array}{l}7853-7905(0,045) \\
7917-8321(0,955)\end{array}$ & $\begin{array}{l}6372-5968(0,954) \\
5956-5904(0,045)\end{array}$ & $\begin{array}{l}\text { Fragmento de Pilrito (?), Quercus } \\
\text { suber, Pinus pinaster/ pinea, } \\
\text { fragmentos indet. }\end{array}$ \\
\hline $97-2$ & $\mathrm{U} 4 \mathrm{a} / \mathrm{MF}$ & CSIC-1514 & c & $7353 \pm 50$ & $\begin{array}{l}8029-8224(0,787) \\
8229-8313(0,213)\end{array}$ & $\begin{array}{l}6364-6280(0,213) \\
6275-6080(0,786)\end{array}$ & Carvão vegetal \\
\hline A1 & $\mathrm{U} 4 \mathrm{a} / \mathrm{MF}$ & CSIC-1620 & c & $7608 \pm 35$ & $\begin{array}{l}8356-8456(0,995) \\
8501-8506(0,005)\end{array}$ & $\begin{array}{l}6557-6552(0,005) \\
6507-6407(0,994)\end{array}$ & Pinus pinaster/ pinea \\
\hline S16b & U4a/ MF & OxA-24779 & AMS & $7792 \pm 34$ & $\begin{array}{l}8459-8468(0,012) \\
8476-8497(0,046) \\
8510-8636(0,942)\end{array}$ & $\begin{array}{l}6687-6561(0,941) \\
6548-6527(0,045) \\
6519-6510(0,012)\end{array}$ & Ramos de angiospérmica indet.* \\
\hline S82 & U5/ M & Wk-16539 & AMS & $8259 \pm 49$ & $\begin{array}{l}9037-9046(0,011) \\
9089-9419(0,989)\end{array}$ & $\begin{array}{l}7470-7140(0,989) \\
7097-7088(0,010)\end{array}$ & $\begin{array}{l}\text { Quercus sp., Pinus pinaster/ pinea, } \\
\text { fragmentos indet. }\end{array}$ \\
\hline S65 & $\mathrm{U} 5 / \mathrm{M}$ & OXA-24782 & AMS & $8317 \pm 37$ & $\begin{array}{l}9145-9172(0,030) \\
9243-9459(0,970)\end{array}$ & $\begin{array}{l}7510-7294(0,970) \\
7223-7196(0,029)\end{array}$ & Prunus sp.* \\
\hline S62 & $\mathrm{U} 5 / \mathrm{M}$ & OXA-24780 & AMS & $8332 \pm 38$ & $9254-9467(1,000)$ & $7518-7305(1,000)$ & Prunus sp.* \\
\hline S5 & U5/M & GrA-15986 & AMS & $8370 \pm 70$ & $\begin{array}{l}9141-9176(0,034) \\
9205-9221(0,011) \\
9238-9526(0,955)\end{array}$ & $\begin{array}{l}7577-7289(0,954) \\
7272-7256(0,011) \\
7227-7192(0,033)\end{array}$ & Quercus sp. \\
\hline S30 & U5/M & GrN-6402 & c & $8380 \pm 60$ & $9255-9526(1,000)$ & $7577-7306(1,000)$ & $\begin{array}{l}\text { Quercus sp., Pinus pinasterl pinea, } \\
\text { Arbutus unedo, fragmentos indet. }\end{array}$ \\
\hline A2 & U5/ M & CSIC-1621 & c & $8397 \pm 38$ & $\begin{array}{l}9304-9364(0,185) \\
9371-9496(0,815)\end{array}$ & $\begin{array}{l}7547-7422(0,815) \\
7415-7355(0,184)\end{array}$ & Carvão vegetal \\
\hline S87 & U5/ M & Wk-16540 & AMS & $8435 \pm 52$ & $\begin{array}{l}9308-9360(0,092) \\
9379-9380(0,001) \\
9397-9534(0,907)\end{array}$ & $\begin{array}{l}7585-7448(0,907) \\
7431-7430(0,000) \\
7411-7359(0,091)\end{array}$ & Quercus sp. \\
\hline s2 & U5a/ EP & GrA-15861 & AMS & $9410 \pm 70$ & $\begin{array}{l}10422-10468(0,025) \\
10478-10798(0,910) \\
10851-10863(0,005) \\
10957-11009(0,030) \\
11016-11067(0,030)\end{array}$ & $\begin{array}{l}9118-9067(0,030) \\
9060-9008(0,029) \\
8914-8902(0,004) \\
8849-8529(0,909) \\
8519-8473(0,025)\end{array}$ & $\begin{array}{l}\text { Pinus sp. (fragmento de pinha } \\
\text { carbonizada) * }\end{array}$ \\
\hline S73 & U5a/ EP & Ua-20495 & AMS & $9525 \pm 70$ & $\begin{array}{l}10593-10625(0,025) \\
10650-11109(0,965) \\
11112-11125(0,010)\end{array}$ & $\begin{array}{l}9176-9163(0,008) \\
9160-8701(0,965) \\
8676-8644(0,025)\end{array}$ & Cf. Fraxinus sp.* \\
\hline
\end{tabular}

Legenda do quadro: Ref. Am. - Referência da amostra; Ref. Lab. - Referência do Laboratório; Rconv. BP - Resultado convencional BP; Cal BC - Datação calibrada BC; “Amostra de "vida curta"/ "longevidade reduzida".

Obs:

O estudo antracológico das amostras S16b, S62, S65 e S95 foi realizado por Mónica Ruiz (CSIC, Espanha). O das restantes é da autoria de Isabel Figueiral (à época investigadora no Centre de Bio-Archéologie et Ecologie da Universidade de Montpellier II, França. Vide Monteiro-Rodrigues, 2008 e 2011).

Em algumas amostras datadas por AMS indica-se que o material datado inclui diversas espécies vegetais. Efectivamente, por motivos de perda acidental de informação durante 0 estudo do material antracológico, nunca nos foi possivel garantir que apenas as espécies de "vida curta" tenham sido datadas. 


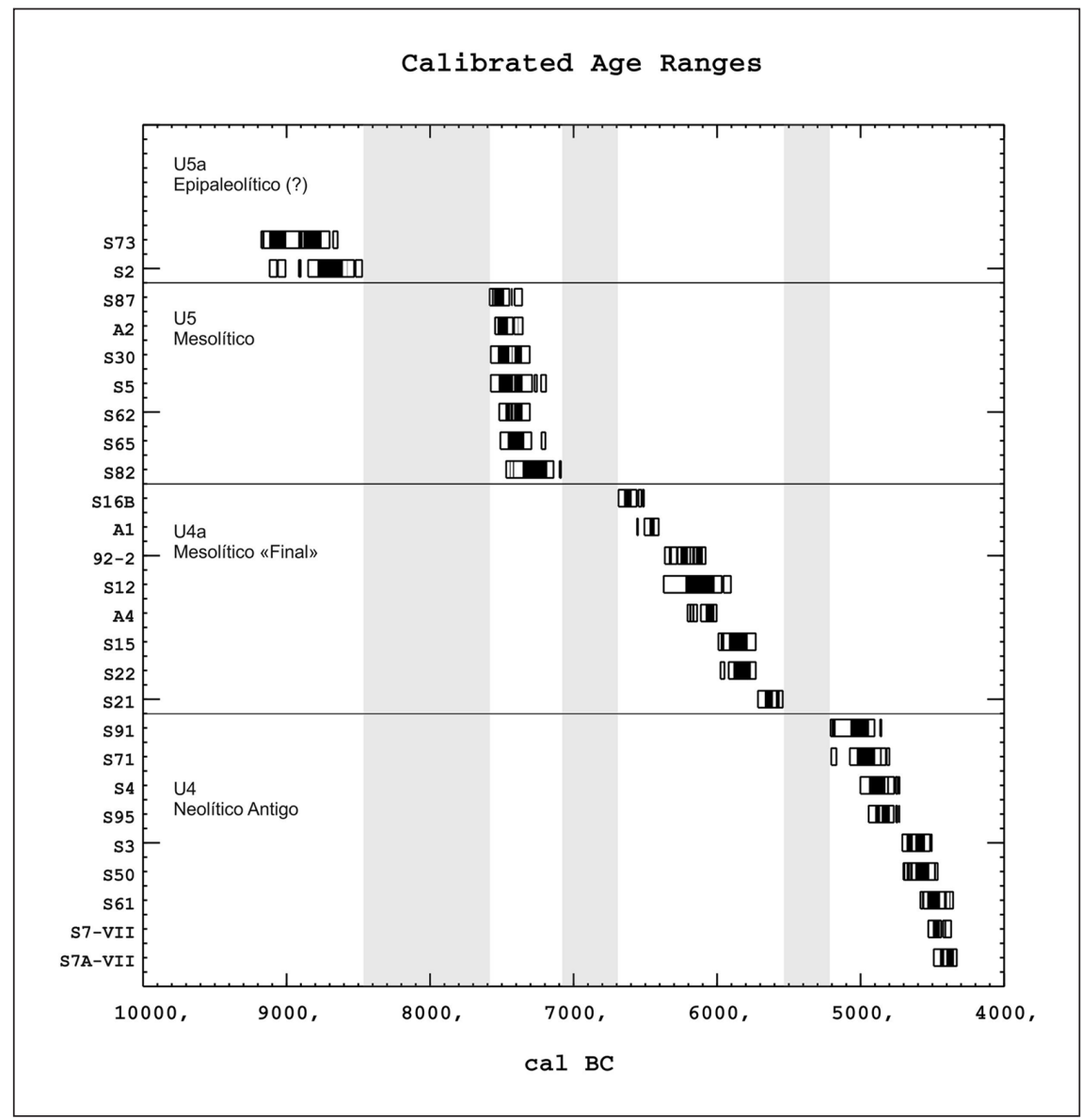

Fig. 7. Cronologia ${ }^{14} \mathrm{C}$ para o sítio pré-histórico do Prazo. Datações calibradas $\mathrm{BC}$ (cal BC). Fig. 7. ${ }^{14} \mathrm{C}$ dating for the prehistoric site of Prazo. Calibrated dates $\mathrm{BC}$ (cal BC).

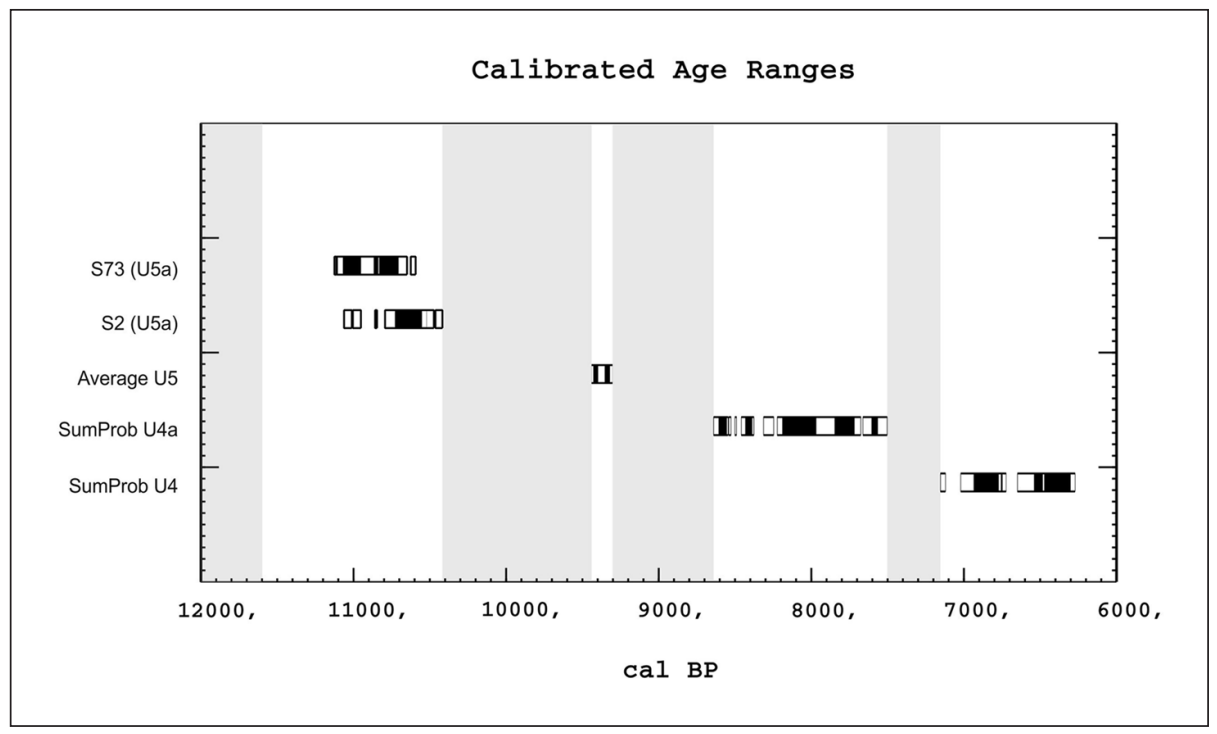

Fig. 8. Cronologia ${ }^{14} \mathrm{C}$ para o sítio pré-histórico do Prazo. Datações calibradas BP (cal BP). Fig. 8. ${ }^{14} \mathrm{C}$ dating for the prehistoric site of Prazo. Calibrated dates BP (cal BP). 
e 97-2 e S22 e S15 permite levantar a hipótese deles se relacionarem com dois dos vários "momentos" em que o Prazo foi ocupado: o primeiro ocorreria entre $\sim 6300-6000$ cal BC e o segundo entre $\sim 6000-5700$ cal BC.

\section{Neolítico Antigo}

As nove datações relativas ao Neolítico Antigo foram obtidas a partir de amostras orgânicas recolhidas nas unidades geoarqueológicas U4 do sector I e U3-VII do sector VII (Fig. 7). Partindo do princípio que as datações testemunham diversas ocupações ocorridas ao longo do tempo, conclui-se que o Prazo terá sido frequentado por grupos humanos entre $\sim 5200$ e $\sim 4340$ cal BC. A soma das distribuições de probabilidade das nove datações, para o grau de confiança de $2 \sigma$, mostra o limite máximo de 5203 cal BC e o mínimo de 4337 cal BC, pelo que as ocupações terão ocorrido dentro de um período de 866 anos. A distribuição de probabilidades para este extenso período incide nos intervalos de 5203-5171 cal BC (2\%), 5073-4781 cal BC (41\%) e 4708-4337 cal BC (57\%).

No que respeita especificamente à datação do sector VII, não é possível assegurar que a respectiva ocupação tenha ocorrido unicamente numa fase tardia do Neolítico Antigo - isto é, entre 4505 e 4337 cal BC $2 \sigma$ (soma das distribuições de probabilidade das datações das amostras S7-VII e S7A-VII; intervalo com $98 \%$ de probabilidade) - uma vez que este local dispõe apenas de duas datações consideradas válidas (Monteiro-Rodrigues 2008, 2011). Do ponto de vista arqueológico, não se observaram diferenças significativas entre este sector e o sector I (idem), pelo que nada impede que também o sector VII conserve vestígios de ampla diacronia. Com efeito, a realização de mais datações poderá fornecer resultados de ${ }^{14} \mathrm{C}$ tão recuados como os obtidos no sector I.

Neste último sector, sobre a unidade U4, existe uma outra unidade com vestígios do Neolítico Antigo - a unidade U3 - para a qual não se dispõe de datações absolutas. Uma vez que a unidade U3 posiciona-se estratigraficamente sobre a unidade U4, e a unidade U3-VII (sector VII) apresenta datações estatisticamente semelhantes às mais recentes da unidade U4 (as datações das amostras S7A-VII, S7-VII, S50 e S61 são estatisticamente semelhantes: $\left.\mathrm{T}=6,94 ; \mathrm{Xi}^{2}(.05)=7,81 ; \mathrm{Gl}=3\right)$, então a unidade U3 do sector I terá de ser necessariamente posterior às outras duas unidades estratigráficas, representando assim a fase mais recente do Neolítico Antigo do Prazo (posterior ao intervalo 4681-4340 cal BC 2o, definido pela soma das distribuições de probabilidade das datações das referidas amostras).

\section{Os Hiatos Cronológicos}

Como se pode observar nas Figuras 7 e 8, entre as várias ocupações identificadas na estação há períodos para os quais não existem datações. A respectiva amplitude temporal é a seguinte: $\sim 1000$ anos entre a unidade U5a e a unidade U5, $\sim 670$ anos entre a unidade U5 e a unidade U4a e $\sim 350$ anos entre a unidade U4a e a unidade U4 (intervalos mínimos).

Muito embora estes "hiatos" cronológicos sugiram, numa primeira abordagem, um padrão de povoamento marcado pela descontinuidade, o facto é que também não se pode afastar a hipótese deles decorrerem da história sedimentar da região, a qual esteve marcada por processos de deposição, estabilidade e erosão ligados, sobretudo, a eventos climáticos e à antropização do território. Efectivamente, em trabalhos anteriores (MONTEIRO-RODRIGUES E ANGELUCCI 2004; MonteIro-Rodrigues 2008, 2010, 2011) avançou-se a possibilidade do truncamento erosivo da sequência plistocénica do Prazo estar relacionado com o Dryas recente ( 12000 cal BP; Fig. 8$)$, que parece ter sido uma fase de erosão generalizada (ANGELUCCI 2002). Por seu turno, a existência de um "hiato" entre a unidade U4a (Mesolítico Final) e a U4 (Neolítico Antigo) foi explicada pela ocorrência de um período de biostasia - testemunhado pelo desenvolvimento de um paleossolo orgânico associável ao óptimo climático do Holocénico médio - durante o qual não terá havido sedimentação capaz de conservar os vestígios arqueológicos da "fase terminal" do Mesolítico Final (MONTEIRO-RodriguES E ANGEluCCI 2004; Monteiro-Rodrigues 2008, 2010, 2011; MONTEIRO-RODRIGUES et al. 2008; LÓPEZ SÁEZ et al. 2006-2007).

Neste mesmo sentido, e no que diz respeito ao vale do Côa, Aubry et al. (2010) demonstraram a articulação entre dinâmicas sedimentares, conservação / não conservação do registo arqueológico e fenómenos paleoambientais. Em relação a estes últimos, consideraram não só indicadores regionais como também outros de âmbito global (p.e. dados paleoclimáticos do Greenland Ice Core Project - GRIP; JOHNSEN et al. 1995, 2001), sugerindo assim a sua influência nos processos geomorfológicos de escala geográfica mais restrita.

Ainda no quadro dos dados paleoclimáticos do GRIP, tem-se chamado a atenção para as consequências dos eventos de 11,200 cal BP (WALKER et al. 1999; MUÑOz SOBRINO et al. 2006) e de 8200 cal BP (BOND et al. 1997, 2001; WALKER et al. 1999; MAYEWSKI et al. 2004) nas coberturas vegetais e em diversas sequências sedimentares, que surgem por vezes truncadas em virtude de processos erosivos decorrentes da aridificação da paisagem (MUÑOZ So- 
BRINO et al. 2006; LÓPEZ SÁEZ 2005; LÓPEZ SAÉZ et al. 2010; LÓPEZ-MERINO et al. 2012; MORENO et al. 2011; CACHO et al. 2010).

Num recente trabalho sobre o processo de neolitização no sul da Península Ibérica foram apresentados diversos indicadores que documentam igualmente os efeitos do evento de 8200 cal BP, bem como de um outro, posterior, que terá estado activo entre $7800 \mathrm{cal}$ BP e 7300 cal BP (evento de 7400 cal BP), e que, aparentemente, se relaciona com o decréscimo da insolação durante os meses de verão no Hemisfério Norte (CORTÉs SÁNCHEZ et al. 2012). De acordo com os autores, este episódio, frio e seco, terá provocado modificações na flora e na fauna, originando também importantes processos erosivos coincidentes, nomeadamente, com a transição Mesolítico - Neolítico Antigo (idem).

Alguns paleoclimatólogos (p.e. FLEITMANN et al. 2008) referem ainda a ocorrência de uma outra anomalia climática em torno de $9200 \mathrm{cal} \mathrm{BP}$, causada por mecanismos semelhantes aos que deram origem ao evento de 8200 cal BP - ou seja, a redução da circulação termoalina provocada pelo aumento do fluxo de água doce no Atlântico Norte. Tal anomalia climática, com expressão no Hemisfério Norte, pode ter sido responsável por alterações ambientais e por fenómenos erosivos logo nos inícios do Holocénico.

Para além dos eventos climáticos, há que ter em conta a antropização da paisagem, que começa a ocorrer de forma mais intensa a partir, genericamente, da segunda metade do VI milénio cal BC e, sobretudo, a partir do V milénio cal BC (p.e. LÓPEZ SÁEZ 2005; LópEz SÁEZ E CRUZ 2006; LÓPEZ SÁEZ et al. 2006-2007, 2010, 2010a; SANCHES et al. 2007; AUBry et al. 2010; MONTEIRO-RODRIGUES 2008, 2011), favorecendo o incremento da erosão, nomeadamente em contextos de vertente.

Em suma, será necessário desenvolver mais estudos na região do Alto Douro para se compreender o real significado dos hiatos cronológicos identificados nos depósitos holocénicos do Prazo.

\section{Conclusões}

Excluindo os vestígios plistocénicos do Prazo, para os quais não existem datações absolutas, as mais antigas evidências da presença humana na estação remontam aos inícios do Holocénico - ou seja, aos finais do X/ meados do IX milénio cal BC. A caracterização cultural desta fase é extremamente difícil dada a exiguidade do respectivo material arqueológico. De referir apenas que no vale do Côa (Fariseu)

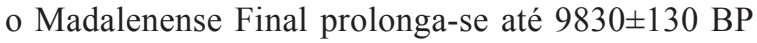

(Ua-32645; 9806-8833 cal BC 2б) ou mesmo até mais tarde (Aubry et al. 2010).

O denominado Mesolítico "antigo" está documentado por "uma" ocupação datada do terceiro quartel do VIII milénio cal BC. A ela associam-se diversas estruturas e uma indústria lítica numericamente significativa (o seu estudo será completado a curto prazo). Já o Mesolítico final parece conservar vestígios de distintas ocupações, ocorridas entre o segundo quartel do VII milénio cal BC e os meados do VI milénio cal BC (MONTEIRO-RodRIGUES 2008 e 2011). Uma melhor caracterização destes períodos, à escala regional, passa pelo desenvolvimento futuro de estudos comparativos com os contextos mesolíticos entretanto identificados no vale do Côa [AUBRY (coord.) 2009].

O Neolítico Antigo está igualmente representado por várias ocupações, que foram ocorrendo entre os finais do VI milénio cal BC e um momento indeterminado posterior ao terceiro quartel do $\mathrm{V}$ milénio cal BC (como se referiu, não foi possível datar o Neolítico Antigo da unidade U3 do sector I, que corresponderá, regionalmente, à fase terminal deste período).

Em síntese, considera-se que as ocupações do Prazo processaram-se no quadro de uma certa intermitência, o que, aliás, é próprio das sociedades de caçadores-recolectores (MONTEIRO-RODRIGUES 2008, 2011; Monteiro-Rodrigues et al. 2008). Como se sublinhou anteriormente, "é possível que se voltasse ao Prazo, mas não se vivesse permanentemente no Prazo, pelo menos durante períodos temporais muito alargados. Por esta razão, os vestígios arqueológicos identificados resultarão de ocupações recorrentes de diversos espaços (que a memória conservou e que as estratégias de exploração dos recursos aconselhavam que se visitasse ciclicamente) no decurso de um tempo longo" (MONTEIRO-RodRIGUES 2008, p. 193).

Relativamente aos hiatos cronológicos, reafirma-se a necessidade de se realizarem mais estudos que os possam explicar. Há que considerar, com efeito, a possibilidade de eles não representarem qualquer despovoamento da região, mas antes serem o resultado de processos naturais e de acções humanas sobre a paisagem.

\section{AGRADECIMENTOS}

Este trabalho enquadra-se no projecto de investigação internacional From shell middens to crop fields: The transition to the Neolithic in the coastal regions of SW Europe - ATLANTMIDDENS (referência: HAR2011-29907-C03-01; 2012-2014), subprojecto de Coastal transitions: A comparative approach to the processes of neolithization in Atlantic Europe - COASTTRAN (referência: HAR2011- 
-29907-C03-00; 2012-2014); Coordenação de Pablo Arias Cabal, Universidade da Cantábria, Espanha. Projecto no âmbito do VI Plan Nacional de Investigación Científica, Desarrollo e Innovación Tecnológica 2008-2011 (Subprograma de Proyectos de Investigación Fundamental no Orientada) do Ministerio de Ciencia e Innovación. O autor agradece aos revisores as correcções e as sugestões que ajudaram a melhorar o texto.

\section{BIBLIOGRAFIA}

ANGELUCCI, D. 2002. The Geoarcheological Context. In J. ZILHÃO \& E. Trinkaus (eds.), Portrait of the Artist as a Child. The Gravettian Human Skeleton from the Abrigo do Lagar Velho. [Trabalhos de Arqueologia, 22]. Lisboa: Instituto Português de Arqueologia: 58-91.

Angelucci, D. \& Monteiro-Rodrigues, S. 2003. Las ocupaciones neolíticas del yacimiento del Prazo (Vila Nova de Foz Côa, Portugal NE). Poster apresentado ao III Congreso del Neolítico en la Península Ibérica (Santander, 5 a 8 de Outubro). Resumo publicado in P. ARIAS, R. ONTAÑón; C. GARCíA-Moncó \& L.C. TeIrA (eds.), III Congreso del Neolítico en la Península Ibérica, Libro Guía de la Excursion. Preactas. Santander: Universidad de Cantabria: 148.

AUBRY, T. (coord.) 2009. 200 séculos da história do Vale do Côa: incursões na vida quotidiana dos caçadores-artistas do Paleolítico. [Trabalhos de Arqueologia, 52]. Lisboa: IGESPAR.

Aubry, Thierry; Dimuccio, luca A.; Mercè Bergadì, M.; SAmpaio, Jorge D. \& Sellami, Farid. 2010. Palaeolithic engravings and sedimentary environments in the Côa River Valley (Portugal): implications for the detection, interpretation and dating of open-air rock art. Journal of Archaeological Science, 37: 3306-3319. (doi:10.1016/j.jas.2010.07.033).

Bernabeu Aubán, J.; Pérez Ripoll, M. \& Martínez, R. 1999. Huesos, Neolitización y Contextos Arqueológicos Aparentes. In J. Bernabeu Aubán \& T. Orozco Köhler (eds.), II Congrés del Neolític a la Península Ibèrica. [Saguntum-Plav, Extra-2]. Valencia: Universitat de València: 589-596.

Bernabeu Auban, J.; Barton, C.M. \& Perez Ripoll, M. 2001. A taphonomic perspective on Neolithic biginnings: theory, interpretation, and empirical data in the Western Mediterranean. Journal of Archaeological Science, 28: 597-612.

Bond, G.; Showers, W.; Cheseby, M.; LotTI, R.; Almasi, P.; Demenocal, P.; Priore, P.; Cullen, H.; Hajdas, I. \& BoNANI, G. 1997. A Pervasive Millennial-Scale Cycle in North Atlantic Holocene and Glacial Climates. Science, 278 (14 Nov): 1257-1266.

Bond, G.; Kromer, B.; Beer, J.; Muscheler, R.; Evans, M. N.; Showers, W.; Hoffmann, S.; LotTi-BOND, R.; HaJdAs, I. \& Bonani, G. 2001. Persistent solar influence on North Atlantic Climate during the Holocene. Science, 294 (7 Dec): 2130-2136.

CACHO, I.; VAlero Garcés, B. \& GonzÁlez SAmpériz, P. 2010. Revisión de las reconstrucciones Paleoclimáticas en la península ibérica desde el último periodo glacial. In F.F. PÉREZ \& R. Boscolo (eds.), Clima en España: pasado, presente y futuro. Informe de evaluación del cambio climático regional. Espanha: Clivar-España: 9-24.

CARvalho, A.F. 2003. A emergência do Neolítico no actual território português: pressupostos teóricos, modelos interpretativos e a evidência empírica. O Arqueólogo Português, série IV, vol. 21: 65-150.
CoRTÉs SÁnchez, M.; JimÉnez Espejo, F.J.; Simón Vallejo, M.D.; Gibaja BaO, J.F.; Carvalho, A.F.; Martinez-Ruiz, F.; Rodrigo Gamiz, M.; Flores, J.-A.; PAytan, A.; LóPeZ SÁez, J.A.; Peña-Chocarro, L.; Carrión, J.S.; Morales MuÑIz, A.; Roselló IzQuierdo, E.; Riquelme Cantal, J.A.; Dean, R.M.; Salgueiro, E.; Martínez SÁnchez, R.M.; De La Rubia De Gracia, J.J.; Lozano Francisco, M.C.; Vera Peláez, J.L.; Llorente Rodríguez, L. \& BICHO, N.F. 2012. The Mesolithic - Neolithic transition in southern Iberia. Quaternary Research, 77: 221-234. (doi:10.1016/ j.yqres.2011.12.003)

Fleitmann, D.; Mudelsee, M.; Burns, S.J.; Bradley, R.S.; KRAMERS, J. \& MATTER, A. 2008. Evidence for a widespread climatic anomaly at around $9.2 \mathrm{ka}$ before presente. Paleoceanography, 23, PA1102: 1-6. (doi:10.1029/2007PA001519, 2008).

JohnSEn, S.J.; DAHL-JENSEN, D.; DANSGAARD, W. \& GUNDESTRUP, N. 1995. Greenland paleotemperatures derived from GRIP bore hole temperature and ice core isotope profiles. Tellus, 47B: 624-629.

JOHNSEN, S.J.; DAHL-JENSEN, D.; GUNDESTRUP, N.; STEFFENSEN, J.P.; Clausen, H.B.; Miller, H.; Masson-Delmotte, V.; SVEINJÖRnSDOTTIR, A.E. \& WhitTE, J. 2001. Oxygen isotope and paleotemperature records from six Greenland ice-core stations: Camp-Century, dye-3, GRIP, GIPS2, Renland and NorthGRIP. Journal of Quaternary Science, 16 (4): 299-307.

Lanting, J.N.; Aerts-Bijma, A.T. \& Van Der Plicht, J. 2001. Dating of cremated bones. In I. CARMI \& E. BOARETTO (eds.), Proceedings of the $17^{\text {th }}$ International ${ }^{14} \mathrm{C}$ Conference. [Radiocarbon, 43 (2A)]. University of Arizona: 249-254.

LÓPEZ SÁEZ, J.A. 2005. Precisiones paleopalinológicas sobre las aparición de la agricultura en la Serra da Estrela (Portugal). Trabalhos de Antropologia e Etnologia, vol. 45, 3-4: 175-183 .

LÓPEZ SÁEZ, J.A.; \& CRUZ, D.J. 2006. Agricultura y antropización del paisaje en Portugal desde una perspectiva palinológica. Coavisão. Cultura e Ciência (Actas do II Congresso de Arqueologia de Trás-os-Montes, Alto Douro e Beira Interior), 8: 41-49.

López SÁEZ, J.A.; Monteiro-Rodrigues, S. \& LÓPEZ MERino, L. 2006-2007. La transición Mesolítico-Neolítico desde una perspectiva paleoambiental: Análisis palinológico del sitio de Prazo (Freixo de Numão, Portugal). Portugalia, Nova Série, Vol. XXVII: 19-34.

López SÁez, J.A.; CruZ, D.J. \& Gonçalves, A.A.H.B. 2010. A Mamoa 1 de Madorras (Sabrosa, Vila Real, Portugal): análises polínicas e datações de Carbono 14. In A.M.S. BETTENCOURT, M.I. Caetano Alves \& S. Monteiro-Rodrigues (eds.), Variações Paleoambientais e Evolução Antrópica no Quaternário do Ocidente Peninsular / Paleoenvironmental Changes and Anthropization in the Quaternary of Western Iberia. Braga: Associação Portuguesa para o Estudo do Quaternário (APEQ) e Centro de Investigação Transdisciplinar Cultura, Espaço e Memória (CITCEM): 39-52.

López SÁez, J.A.; López Merino, L. \& Pérez díAz, S. 2010a. Neolitización, Megalitismo y Antropización del paisaje en Galicia entre el VII y el IV milenio cal BC. Munibe, 32: 488-496.

LÓPEZ-MERINo, L.; Silva SÁnCheZ, N.; KAAL, J.; LóPEZ-SÁeZ, J.A. \& MARTínEZ CORTIZAS, A. 2012. Post-disturbance vegetation dynamics during the Late Pleistocene and the Holocene: An example from NW Iberia. Global and Planetary Change, 92-93: 58-70. (doi:10.1016/j.gloplacha.2012.04.003).

MAYewski, P.A.; Rohling; E.E.; STAGer; J. CURT; KARLÉn, W.; MaAsch, K.A.; MeEKer, L.D.; Meyerson, E.A.; Gasse, F.; 
VAn Kreveld, S.; Holmgren, K.; LeE-ThorP, J.; RosQVist, G.; RACK, F.; STAUBWASSER, M.; SCHNEIDER, R.R. \& STEIG, E. 2004. Holocene climate variability. Quaternary Research, 62: 243-255. (doi:10.1016/j.yqres.2004.07.001).

Monteiro-Rodrigues, S. 2000. A Estação Neolítica do Prazo (Freixo de Numão - Norte de Portugal) no contexto do Neolítico Antigo do Noroeste Peninsular. Algumas considerações preliminares. Actas do 3. ${ }^{\circ}$ Congresso de Arqueologia Peninsular (Vila Real, 22-26 de Setembro de 1999), Vol. III. Porto: ADECAP: 149-180.

Monteiro-Rodrigues, S. 2002. Estação Pré-histórica do Prazo - Freixo de Numão - Estado actual dos conhecimentos. Côavisão, 4: 113-126.

Monteiro-Rodrigues, S. 2008. Pensar o Neolítico Antigo. Contributo para o Estudo do Norte de Portugal entre o VII e o $V$ milénios $B C$. Dissertação de Doutoramento apresentada à Faculdade de Letras da Universidade do Porto, policopiado.

MonteIro-Rodrigues, S. 2010. Algumas considerações acerca do Processo de Neolitização no Norte de Portugal. In A.M.S. Bettencourt, M.I. CAetano Alves \& S. Monteiro-RodriGUES (eds.), Variações Paleoambientais e Evolução Antrópica no Quaternário do Ocidente Peninsular / Paleoenvironmental Changes and Anthropization in the Quaternary of Western Iberia. Braga: Associação Portuguesa para o Estudo do Quaternário (APEQ) e Centro de Investigação Transdisciplinar Cultura, Espaço e Memória (CITCEM): 73-82.

Monteiro-Rodrigues, S. 2011. Pensar o Neolítico Antigo. Contributo para o Estudo do Norte de Portugal entre o VII e o $V$ milénios a. C.. [Estudos Pré-históricos, 16]. Viseu: Centro de Estudos Pré-históricos da Beira Alta.

Monteiro-Rodrigues, S. \& AngelucCi, D. 2004. New data on the stratigraphy and chronology of the prehistoric site of Prazo (Freixo de Numão). Revista Portuguesa de Arqueologia, vol. 7, n. $^{\circ} 1: 39-60$.

Monteiro-Rodrigues, S.; Figueiral, I. \& López SÁez, J.A. 2008. Indicadores paleoambientais e estratégias de subsistência no sítio pré-histórico do Prazo (Freixo de Numão - Vila Nova de Foz Côa - Norte de Portugal). In Pré-história. Gestos intemporais. Actas do III Congresso de Arqueologia de Trás-os-Montes, Alto Douro e Beira Interior, Vol. I Vila Nova de Foz Côa: ACDR - Freixo de Numão: 96-119.

Moreno, A.; López-Merino, L.; LeIra, MANEL; MARCo-BARBA, J.; GONZÁLEZ-SAMPÉRIZ, P.; VALERO-GARCÉS, B.L.; LÓPEZ-SÁEZ, J.A.; SAntos, L.; MATA, P. \& ITO, E. 2011. Revealing the last 13,500 years of environmental history from the multiproxy record of a mountain lake (Lago Enol, northern Iberian Peninsula). Journal of Paleolimnology (J Paleolimnol), 46: 327-349. (DOI 10.1007/s10933-009-9387-7).
Muñoz Sobrino, C.; RAMil-Rego, P. \& Gómez-Orellana, L. 2007. Late Würm and early Holocene in the mountains of northwest Iberia: biostratigraphy, chronology and tree colonization. Vegetation, History and Archaeobotany (Veget Hist Archaeobot), 16: 223-240. (DOI 10.1007/s00334-006-0083-5).

ReImer, P.J.; BAIllie, M.G.L.; BARD, E.; BAyliss, A.; BeCK, J.W.; BlackWell, P.G.; Ramsey, C. Bronk; Buck, C.E.; BURR, G.S.; EDWARdS, R.L.; FrIEDRICH, M.; GroOTES, P.M.; Guilderson; T.P.; Hajdas, I.; Heaton, T.J.; HogG; A.G.; Hughen, K.A.; KAISER; K.F.; Kromer, B.; MCCORMAC, F.G.; MANNING, S.W.; REIMER, R.W.; RICHARDS, D.A.; SOUTHON, J.R.; TAlamo, S.; Turney, C.S.M.; VAN Der Plicht, J. \& Weyhenmeyer, C.E. 2009. IntCal09 and Marine09 Radiocarbon Age Calibration Curves, 0-50,000 years cal BP. Radiocarbon, 51 (4): 1111-1150. http://researchcommons. waikato.ac.nz/bitstream/10289/3622/1/Hogg\%20Intcal09\%2 0and\%20Marine09.pdf.

SANCHES, M.J.; NunES, S.A. \& PINTO, D.B. 2007. Trás-os-Montes (Norte de Portugal). As gentes e os ecossistemas do Neolítico à Idade do Ferro. In S.O. Jorge; A.M.S. BetTencourT \& I. Figueiral (eds. científicos), A Concepção das Paisagens e dos Espaços na Arqueologia da Península Ibérica, Actas do IV Congresso de Arqueologia Peninsular [Promontoria Monográfica, 8]. Faro: Centro de Estudos do Património da Universidade do Algarve: 189-206.

Stuiver, M. \& Reimer, P.J. 1993. Extended ${ }^{14} \mathrm{C}$ database and revised CALIB radiocarbon calibration program. Radiocarbon, 35: 215-230.

Stuiver, M.; ReImer, P.J. \& Reimer, R.W. 1986-2011. CALIB Radiocarbon Calibration Rev. 6.0.1 (Program and Documentation). http://calib.qub.ac.uk/calib/.

TEXIER, J.-P. 2000. À propos des processus de formation des sites préhistoriques. Paleo, 12: 379-386.

WALKer, M.J.C.; BJÖRCK, S.; LOWE, J.J.; CWYNAR, L.C.; Johnsen, S.; KNUDSEn, K.-L.; WohlFARTh, B. \& Intimate GROUP. 1999. Isotopic "events" in the GRIP ice core: a stratotype for the Late Pleistocene. Quaternary Science Reviews, 18: $1143-1150$.

WARD, G.K. \& WiLSON, S.R. 1978. Procedures for comparing and combining radiocarbon age determinations: a critique. Archaeometry, 20: 19-31.

WILSON, R. \& WARD, G.K. 1981. Evaluation and clustering of radiocarbon age determinations: procedures and paradigms. Archaeometry, 23 (1): 19-39.

ZILHÃO, J. (2001). Radiocarbon evidence for maritime pioneer colonization at the origins of farming in west Mediterranean Europe. Proceedings of the National Academy of Sciences (USA), vol. 98, n. ${ }^{\circ}$ 24: 14180-14185. 